\title{
Nurses communication skill and associated factors in Amhara Region Referral Hospitals, Ethiopia, 2019
}

Kassahun Gebeyehu Yazew ( $\nabla$ kassish6@gmail.com )

University of Gondar College of Medicine and Health Sciences https://orcid.org/0000-0001-9324-3842

Mignot Hailu Gebrie

University of Gondar College of Medicine and Health Sciences

Zewdu Bishaw Aynalem

Bahir Dar University College of Medical and Health Sciences

Research

Keywords: Communication skills, Nurses, Patients, Ethiopia

Posted Date: February 19th, 2020

DOI: https://doi.org/10.21203/rs.2.23987/v1

License: (c) (i) This work is licensed under a Creative Commons Attribution 4.0 International License.

Read Full License 


\section{Abstract}

Background: - Nurses are critical in the delivery of essential health services and are core in strengthening the health system. So, the aim of this article was to assess the prevalence of the communication skills of the nurses to patient and determinant factors in Amhara Region Referral Hospitals, Ethiopia, 2019

Methods: Institution based cross-sectional study was conducted from March 18 to April 16, 2019 in Amhara Region Referral Hospitals. A simple random sampling technique was used to select 684 respondents. Data was collected using pretested and self-administered questionnaire. Collected data was entered into Epi Info version 7.1.2.0 and exported to SPSS version 25.0 for analysis. Bivariate analysis was used primarily and variables with $p$-value $\leq 0.2$ were further examined using multivariable logistic regression model to control con-founders. Then, variables having p-value less than 0.05 with $95 \% \mathrm{Cl}$ were used to determine associated factors.

Results: - Out of 678 study participants, 403 (61.4\%) of them had effective communication skills with $96.8 \%$ of the response rate. Less than 5 years of working experience [AOR=2.77; 95\% Cl: $(1.28,5.99)]$, workload [AOR=1.52; 95\% Cl: $(1.09,2.12)$ ], and poor evidence-based utilization [AOR=2.00; $95 \% \mathrm{Cl}$ : $(1.40$, 2.85)] were associated with the nurse's effective communication skill to patients.

Conclusions: More than half of the participants were had effective communication skills. Year of working experience, workload, and poor evidence-based utilization were the main contributing factors of the communication skills. Keywords: Communication skills, Nurses, Patients, Ethiopia

\section{Background}

In delivering of the essential health services and solidification of the health system are the main roles of the Nurses (1). Communication skills are an important element in nursing care and nursing education. Nurses have paid a lot of consideration to communication and interaction in nursing since $19^{\text {th }}$ century at the time of Florence Nightingale (2). Appropriate communication is one of the patient's critical needs and the basis for nursing care (3) and again effective communication is the most important factor in maintaining the quality of nursing care (4). It performs the most important role between the nurses and clients (5).

Ineffective communication is usually a potential barrier to providing services in caring settings (6). The desirable outcome of a verbal interaction process is effective communication, where the receiver understands the sender's message as it was intended (7).

The nature of the interpersonal relationships between nurses and patients, as well as its effect on patient care, is critical in health care service delivery, to ensure that the patients' expectations are met, or exceeded (8). Healthy communication between providers and patients may predispose patients to release relevant information and to obey to prescribed treatment (9). In health care setting, effective communication assures the healthier psychological position by managing the disease, controlling the 
pain, recalling the history of the disease and improving the satisfaction of the clients (10). A health professional must therefore, continuously try to advance his/her communication skills as ineffective message can be a challenging and lead to confusion. So, to tackle those problems nurses are confronted daily with excessive duties due to high patient numbers and the nature of the health care environment (11). Thus, might lead to the communication abortive during care giving.

From Canada, patients were dissatisfied due to Nurses to patients ineffective Communication (12).

Care receivers with communication challenges were a more likely to manifest medical or clinical complications related to other receivers (13).

The communication problems among general population were $5-10 \%$, whereas over $15 \%$ in Hospital admissions $(14,15)$. In a different studies, the prevalence of the Nurse to patient communication skill was described that in Iran good communication skills 14.3\% (16), Tabriz $94.7 \%$ (17), Greece $41.3 \%$ (18), Korea $75 \%$ (19) and Ethiopia $34.5 \%$ (20). Accordingly, poor quality of care is prevalent due to such ineffective communication skills. So, in United kingdom researchers tried to improve communication skills with interprofessional team learning to maintain patient safety (21).

Several factors that influence communication skills between Nurse and patients have been examined, such as working experience, environmental barriers, gender differences, work crowdedness, work load, insufficient time and utilizing $\operatorname{EBP}(3,22-26)$.

A systematic review explained that the nurses communication skills were negatively influenced with their excessive work during activities (27).

A cross-sectional study from Iran explained that disorganized environment was significantly associated with communication skills (12).

Regardless of strong emphasis on training and improving the caregiver's communication skills, there are still noticeable lacks and therefore effective communication is restricted by a number of organized factors (2).

To enhance health care and decrease patients' dissatisfaction, the factors that affect communication between nurses and patients must be recognized and taken into account; also, response to all communication needs of patients should be provided (28). Therefore, this study was aim to assesses the associated factors with the Nurse to patient communication skill at Amhara Region Referral Hospital, Ethiopia, 2019.

\section{Methods}

\section{Study design and setting}


An institution based cross-sectional study was employed among nurses working in Amhara Regional state Referral Hospitals, Ethiopia. This region has five Referral Hospitals which includes; Debre Birhan, Debre Markos, Felege Hiwot, Gondar University comprehensive and specialized and Dessie Referral Hospitals. Each of them serving 3.5-7 million people (29).

\section{Source and study population}

All nurses who were working in Amhara Region Referral Hospitals and at list who had 6 months of working experience during data collection period were included. Whereas Nurses who were on maternity or annual leave or those who were seriously ill during the data collection period were excluded.

The sample size was determined by using single population proportion formula with the assumption of: nurses' level of communication $65.5 \%$ (20) proportion, $Z$ = standard normal distribution value at $95 \%$ confidence level of $\mathrm{Za} / 2=1.96$ and $5 \%$ margin of error for first objective. This gave 347.1 plus 35 nonresponse rate equals to 382 . Whereas Sample size for the second objective was determined by using double population proportion formula for cross-sectional study by considering the following assumptions taking two significant factors from the previous study (20) (Table 1). So, the largest sample size with power calculation was 678 , which is higher than the sample size calculated from the single population proportion formula above. Thus, the minimum adequate sample size for this study was 678 .

Of the 1465 Nurses working in the Amhara Regional Referral Hospitals, Ethiopia, 678 of them were recruited for the study at the time of data collection. Study participants were included using a simple random sampling procedure.

\section{Data Collection}

Data were collected by five trained BSc nurses that facilitates the process of filling pretested selfadministered questionnaires and supervised by three MSc nurses. The data collection instrument had different components: socio-demographic characters, working environment attributes and nurse patient communication skills of the participants using a checklist that was developed on the basis of various prior similar studies and further modified to include important variables of this study to $\mathrm{ft}$ the study area context $(20,30)$. Sixteen questions were adapted from a previous study $(30)$ to measure the effectiveness of nurses' communication skill with the patient. Each item had a 5-point Likert scale ( $1=$ strongly disagree, 2 = disagree, $3=$ neutral, $4=$ agree and $5=$ strongly agree) with a minimum score of 16 and a maximum score of 80 .

\section{Operational definition}

Communication: Respondents who scored the median of communication questions was considered effective and below the median was considered as ineffective communication (30).

\section{Data processing and analysis}


The collected data was cleaned, checked for its completeness, categorized, coded, and entered to Epi Info version 7.2.1.0 software. Then, it was exported to SPSS version 25.0 for analysis. Bivariate analysis was done to see the association of each independent variable with the outcome variable at $P \leq 0.2$. The AOR with $95 \% \mathrm{Cl}$ was calculated to determine the association at $\mathrm{P}<0.05$ and considered statistically significant. Finally, data were presented in tables and texts.

\section{Results}

\section{Socio-Demographic characteristics}

A total of 656 Nurses participated in this study from 678 sampled participants with $96.8 \%$ response rate. Out of the total participants, 19 (3.2\%) were non respondents. The study consisted of $335(51.1 \%)$ males. The participants mean and standard deviation for age were $31.22 \pm 5.565$ years respectively. Among study participants $439(66.9 \%)$ and 217 (33.1\%) were ever married and single respectively. Of the nurses working in different units $27.6 \%, 26.4 \%, 19.4 \%, 11.3 \%, 9.8 \%, 5.5 \%$ were at Medicine, Surgical, Ambulatory, Pediatric, Emergency and critical units respectively (Table 2).

\section{Organizational and other related factors}

In this study, mean and standard deviation (SD) of the patient to nurse ratio was $8.79 \pm 2.50$ respectively and more than half $56.4 \%$ were those $\geq 7$. Out of the total 656 respondents, 358 (54.6\%) and 298 (45.4\%) had good and poor evidence-based practice utilization with the mean and SD $16.62 \pm 6.04$ respectively. The majority of the participants 511 (77.9\%) were took training or courses on communication skills. Of the respondents, $357(54.3 \%)$ and $400(61 \%)$ were had work load and lack of time to communicate effectively during their activities.

\section{Prevalence of the nurse-patient effective communication skills}

The prevalence of the nurse to patient communication skills among participants was $38.6 \%$ had effective communication whereas $61.4 \%$ had ineffective communication skills.

\section{Factors Associated with Nurse to patient communication skills.}

All independent variables were entered in to the bivariate logistic regression model and variables with $p \leq$ 0.2 were entered into the multivariable analysis. After controlling possible confounding effects of other covariates, age, working experience, presence of enough time, training on communication, work load, utilization of the evidence-based practice and patient to nurse ratio were had a significant association at 95\% confidence level (Table 3 ).

\section{Discussion}

Effective communication between nurses and patients is one of the most essential components for raising patient satisfaction, treatment compliance and health products (31). Hence, this study revealed 
that the proportion of the Nurse to patient effective communication skill was $61.4 \%$ with the $95 \% \mathrm{Cl}$ $(57.6 \%, 65.2 \%)$. The finding of this study was lower than studies done in Korea $75 \%(19)$. In contrast, the current finding was higher than studies done in Iran $14.3 \%$ (16) and Ethiopia 34.5\% (20). The variation might be due to the difference in study design, data collection tool, and sample size in study participants.

The finding was also identified as different significant factors that had an association with Nurse to patient communication skills. With respect to year of experience, less than five years of service was significantly associated with Nurse to patient communication skill. Those with less than five years of working experience were 2.77 [ $\mathrm{AOR}=2.70(95 \% \mathrm{Cl}=1.28,5.99)]$ times more likely to be ineffective on communication than those who had more than ten years of working experiences, which was similar to the study done in Saudia Arabia (26). The possible reason for this might be frequently practicing or communicating with client for long period can predispose nurses to perform their duties effectively.

The other factor that had a significant association with Nurse to patient communication skill was the work load. In this study, participants with work load were about 1.52 [AOR $=1.52(95 \% \mathrm{Cl}=1.09,2.12)$ ] times more likely to have ineffective communication than those who had no work load. This study was supported by studies done in Iran. Health professionals who had work load showed ineffective communication with clients $(32,33)$. The possible justification for this one high workload might causes nurses have short time to communicate with clients and it also causing negative interaction between nurses and client.

The odds of Nurse to patient communication skill were about 2.00 [AOR $=1.90 ;(95 \% \mathrm{Cl}=1.40,2.85)$ ] times ineffective among individuals who had poor EBP utilization as compared to those who had good EBP utilization. This result was supported by studies done in Switzerland (25) which was described that, Nurses faced with many personal barriers to integrate evidence into practice and to have quality of working relationships. So, Nurses must increase their professional knowledge by utilizing EBP for engagement in continuous learning to sustain an effective communication with colleagues, cooperating in teams and providing a high level of nursing care for patients. The reason might be that those nurses who had poor EBP utilization were influenced by negative response and it also plays a crucial role in the disturbance of the message receiving and sending communication process.

\section{Conclusions}

More than half of the participants were had effective communication skills. Year of working experience, workload, and poor evidence-based utilization were the main contributing factors of the Nurse to patient communication skills. So, responsible bodies (Government, health institutions, etc....) should pay attention to work on those factors and improve the Nurses communication skill during care giving.

\section{Abbreviations}


adjusted odds ratio, COR:crude odds ratio, Cl:confidence interval, EBP:Evidence-based practice, SD:standard deviation

\section{Declarations}

We declare that this is an original paper and any comments regarding the manuscript will be accepted by Kassahun Gebeyehu, E-mail address: Kassish6@gmail.com.

\section{Ethics approval and consent to participate}

Ethical clearance was obtained from the Ethical Review Committee of the School of Nursing, College of Medicine and Health Sciences, University of Gondar and written consent was taken from participants.

\section{Data availability}

The data used to support the findings of this study are available from the corresponding author upon request.

\section{Funding}

This research article was funded by University of Gondar.

\section{Acknowledgments}

We thank the University of Gondar for the approval of the ethical clearance and for their technical and financial support of this study. This research article was funded by the University of Gondar. Also, our gratitude goes to our family and our friends. And finally, to the study participants, supervisors, and data collectors.

\section{Consent to publish}

Written informed consent for publication was obtained.

\section{Competing interests}

The authors declare that they have no competing interests.

\section{Authors' Contributions}

Kassahun Gebeyehu Yazew, principal investigator of the study, carried out the manuscript from its conception, analysis, and interpretation of data and drafted the manuscript. Zewdu Bishaw and Mignote Hailu participated in reviewing the proposal, tool evaluation, interpretation, and critical review of the draft of the manuscript. All authors read and approved the final draft of the manuscript.

\section{Authors' information}


KG is a Lecturer and a Nurse Practitioner in the School of Nursing, College of Medicine and Health Sciences at University of Gondar, Ethiopia. He has a Bachelor of Science

Degree in Nursing, MSc in Advanced Clinical medical Nursing.

MH is a Lecturer and a Nurse Practitioner in the School of Nursing, College of Medicine and Health Sciences at University of Gondar, Ethiopia. She has a Bachelor of Science

Degree in Nursing, MSc in Advanced Clinical Surgical Nursing. She is a PhD student at School of Nursing, University of Gondar.

ZB is a Lecturer and a Nurse Practitioner in the Department of Nursing, College of Medicine and Health Sciences at Bahirdar University, Ethiopia. He has a Bachelor of Science Degree in Nursing, MSc in Advanced Clinical Medical Nursing.

\section{References}

1. Organization WH. Global strategic directions for strengthening nursing and midwifery 2016-2020. 2016.

2. Fleischer S, Berg A, Zimmermann M, Wüste K, Behrens J. Nurse-patient interaction and communication: A systematic literature review. Journal of Public Health. 2009;17(5):339-53.

3. Aghabarari M, Mohammadi I, VARVANI FA. BARRIERS TO APPLICATION OF COMMUNICATIVE SKILLS BY NURSES IN NURSE-PATIENT INTERACTION: NURSES AND PATIENTS'PERSPECTIVE. 2009.

4. Mullan BA, Kothe EJ. Evaluating a nursing communication skills training course: The relationships between self-rated ability, satisfaction, and actual performance. Nurse education in practice. 2010;10(6):374-8.

5. Itri JN, Yacob S, Mithqal A. Teaching communication skills to radiology residents. Current problems in diagnostic radiology. 2017;46(5):377-81.

6. Fakhr-Movahedi A, Salsali M, Negarandeh R, Rahnavard Z. Exploring contextual factors of the nursepatient relationship: A qualitative study. Koomesh. 2011:23-34.

7. Lunenburg FC. Communication: The process, barriers, and improving effectiveness. Schooling. 2010;1(1):1-10.

8. Kourkouta L, Papathanasiou IV. Communication in nursing practice. Materia socio-medica. 2014;26(1):65.

9. Doyle C, Lennox L, Bell D. A systematic review of evidence on the links between patient experience and clinical safety and effectiveness. BMJ open. 2013;3(1):e001570.

10. Marhamati S, Amini M, Mousavinezhad H, Nabeiei P. Design and validating the nurse-patient communication skills questionnaire. Journal of Health Management \& Informatics. 2016;3(2):57-63. 
11. MacPhee M, Dahinten VS, Havaei F. The impact of heavy perceived nurse workloads on patient and nurse outcomes. Administrative Sciences. 2017;7(1):7.

12. Norouzinia R, Aghabarari M, Shiri M, Karimi M, Samami E. Communication barriers perceived by nurses and patients. Global journal of health science. 2016;8(6):65.

13. Bartlett G, Blais R, Tamblyn R, Clermont RJ, MacGibbon B. Impact of patient communication problems on the risk of preventable adverse events in acute care settings. Cmaj. 2008;178(12):155562.

14. Ruiters KW. The communication challenges between nurses and patients in an urban emergency centre in the Western Cape. 2017.

15. Downey D, Happ MB. The need for nurse training to promote improved patient-provider communication for patients with complex communication needs. Perspectives on Augmentative and Alternative Communication. 2013;22(2):112-9.

16. Rostami H, Mirzaei A, Golchin M. EVALUATION OF COMMUNICATION SKILLS OF NURSES FROM HOSPITALIZED PATIENTS'PERSPECTIVE. The Journal of Urmia Nursing and Midwifery Faculty. 2012;10(1):27-34.

17. Mogadasian S, Firoziyan A, Nikanafar A, Rahmani A, Abdolahzadeh F. Satisfaction with nursing care and related factors in hospitalized cancer patients in shahid ghazi hospital in tabriz. The Journal of Urmia Nursing and Midwifery Faculty. 2013;11(7):498-506.

18. Peleki T, Resmpitha Z, Mavraki A, Linardakis M, Rikos N, Rovithis M. Assessment of Patients and Nurses' Opinions on the Bidirectional Communication During Hospitalization: A Descriptive Study. Health Science Journal. 2015;9(3):1.

19. Park E-k, Song M. Communication barriers perceived by older patients and nurses. International journal of nursing studies. 2005;42(2):159-66.

20. Wune G. Assessent of nurses to patients communication and barriers percived by nurses at Tikur Anbessa specilized hospital, Addis Ababa, Ethiopia 2018. 2018.

21. Edwards S, Siassakos D. Training teams and leaders to reduce resuscitation errors and improve patient outcome. Resuscitation. 2012;83(1):13-5.

22. Van Kleef J. PLAR: Finding quality in the dynamics of social practice. PLA Inside Out: An International Journal on Theory, Research and Practice in Prior Learning Assessment. 2012;1(2).

23. Aghamolaei T, Hasani L. Communication barriers among nurses and elderly patients. Hormozgan Medical Journal. 2011;14(4):312-8.

24. Alotaibi B. Nurses Communication Barriers in Healthcare Centers: Patientsâ€ $€^{\mathrm{TM}}$ Perspectives. International Journal of Nursing Didactics. 2018;8(01):24-34.

25. Mascherek AC, Schwappach DL. Patient safety climate profiles across time: Strength and level of safety climate associated with a quality improvement program in Switzerland-A cross-sectional survey study. PloS one. 2017;12(7):e0181410. 
26. Albagawi BS, Jones LK. Quantitative exploration of the barriers and facilitators to nurse-patient communication in Saudia Arabia. Journal of Hospital Administration. 2017;6(1):16.

27. Andriyanto A. Communication barrier between nurse and patient at the hospital: a systematic review. Journal of Health Policy and Management. 2019;4(2):105-10.

28. Rodin G, Mackay JA, Zimmermann C, Mayer C, Howell D, Katz M, et al. Clinician-patient communication: a systematic review. Supportive Care in Cancer. 2009;17(6):627-44.

29. Health FDRoEMo. Health Sector Development Program IV, 2010/11-2014/15. Ministry of Health Addis Ababa; 2010.

30. Ayman M, Ahmad E, Imad N, Wisam M, Saleh N, Muna A. Patients' satisfaction about nurses' competency in practicing communication skills. Life Science Journal. 2014;11(3):339-34.

31. Shukla AK, Yadav VS, Kastury N. Doctor-patient communication: an important but often ignored aspect in clinical medicine. Journal of the Indian Academy of Clinical Medicine. 2010;11:208-11.

32. Anoosheh M, Zarkhah S, Faghihzadeh S, Vaismoradi M. Nurse-patient communication barriers in Iranian nursing. International nursing review. 2009;56(2):243-9.

33. Kingma M. Nurses on the move: a global overview. Health services research. 2007;42(3p2):1281-98.

\section{Tables}

Table 1: Sample size determination for associated factors of nurse to patient communication skills in Amhara Region Referral Hospitals, Ethiopia, 2019

\begin{tabular}{|c|c|c|c|c|c|c|c|c|c|}
\hline Jo & $\begin{array}{l}\text { Associated } \\
\text { Factors }\end{array}$ & $\begin{array}{l}\text { Non- } \\
\text { exposed } \\
\text { (p1) }\end{array}$ & $\begin{array}{l}\text { Exposed } \\
\text { (p2) }\end{array}$ & $\begin{array}{l}\text { Confidence } \\
\text { level (\%) }\end{array}$ & $\begin{array}{l}\text { Power } \\
\text { (\%) }\end{array}$ & $\begin{array}{l}\text { Odds } \\
\text { ratio }\end{array}$ & $\begin{array}{l}\text { Sample } \\
\text { size }\end{array}$ & $\begin{array}{l}10 \% \text { non- } \\
\text { response }\end{array}$ & $\begin{array}{l}\text { Final } \\
\text { sample } \\
\text { size }\end{array}$ \\
\hline & $\begin{array}{l}\text { Lack of interest } \\
\text { to work }\end{array}$ & 44.2 & 55.8 & 95 & 80 & 1.59 & 616 & 62 & 678 \\
\hline & Work load & 29.9 & 70.1 & 95 & 80 & 5.50 & 622 & 56 & 62 \\
\hline
\end{tabular}

Table 2: Socio-demographic characteristics of nurses working in Amhara region Referral Hospitals, Ethiopia, 2019 


\begin{tabular}{llrr}
\hline variables & Categories & Frequency & Percentage \\
\hline Age & $21-30$ & 430 & 65.5 \\
& $31-40$ & 157 & 23.9 \\
\cline { 2 - 4 } & $41-50$ & 57 & 8.7 \\
\cline { 2 - 4 } Educational level & $51-60$ & 12 & 1.8 \\
\hline & MSc Nurse & 36 & 5.5 \\
\cline { 2 - 4 } & BSc Nurse & 559 & 85.2 \\
\cline { 2 - 4 } & Diploma Nurse & 61 & 9.3 \\
\hline Place of education completion & Government institutions & 584 & 89.0 \\
\cline { 2 - 4 } & Private institutions & 72 & 11.0 \\
\hline Work experience & $<5$ & 319 & 48.6 \\
\cline { 2 - 4 } & $5-10$ & 213 & 32.5 \\
\cline { 2 - 4 } & $>10$ & 124 & 18.9 \\
\hline Monthly salary & $<4650$ & 168 & 25.6 \\
\hline & $4650-5294$ & 168 & 25.6 \\
\cline { 2 - 4 } & $5294-7111$ & 196 & 29.9 \\
\cline { 2 - 4 } & $>7111$ & 124 & 18.9 \\
\hline
\end{tabular}

Table 3 : Bivariate and multivariate logistic regression output for factors associated with nurse to patient communication skills in Amhara Region Referral Hospitals, Ethiopia, 2019 (n=656).

\begin{tabular}{|c|c|c|c|c|c|c|}
\hline \multirow[t]{2}{*}{ Variables } & \multirow[t]{2}{*}{ Categories } & \multicolumn{2}{|c|}{ Communication skill } & \multirow[t]{2}{*}{ AOR $(95 \% \mathrm{CI})$} & \multirow[t]{2}{*}{ COR $(95 \% \mathrm{CI})$} & \multirow[t]{2}{*}{ P-value } \\
\hline & & Effective & Ineffective & & & \\
\hline \multirow[t]{4}{*}{ Age } & $21-30$ & 286 & 144 & $0.99(0.29,3.35)$ & $0.34(0.08,1.42)$ & 0.14 \\
\hline & $31-40$ & 88 & 69 & $0.64(0.18,2.21)$ & $0.45(0.12,1.71)$ & 0.24 \\
\hline & $41-50$ & 21 & 36 & $0.29(0.08,1.09)$ & $0.31(0.08,1.21)$ & 0.09 \\
\hline & $51-60$ & 8 & 4 & 1 & 1 & \\
\hline \multirow[t]{3}{*}{ Experience } & $<5$ & 224 & 95 & $3.06(1.99,4.69)$ & $2.77(1.28,5.99)$ & 0.01 \\
\hline & $5-10$ & 125 & 88 & $1.84(1.18,2.88)$ & $1.58(0.81,3.08)$ & 0.18 \\
\hline & $>10$ & 54 & 70 & 1 & 1 & \\
\hline \multirow[t]{2}{*}{ Lack of time } & Yes & 173 & 83 & $0.65(0.47,0.90)$ & $0.81(0.57,1.15)$ & \multirow[t]{2}{*}{0.23} \\
\hline & No & 230 & 170 & 1 & & \\
\hline \multirow[t]{2}{*}{ Communication training } & No & 303 & 208 & $0.67(0.44,0.97)$ & $0.94(0.61,1.44)$ & \multirow[t]{2}{*}{0.77} \\
\hline & Yes & 100 & 45 & 1 & 1 & \\
\hline \multirow[t]{2}{*}{ Work load } & Yes & 157 & 113 & $0.79(0.58,1.09)$ & $1.52(1.09,2.12)$ & \multirow[t]{2}{*}{0.01} \\
\hline & No & 246 & 140 & 1 & 1 & \\
\hline \multirow[t]{2}{*}{ EBP utilization } & Good & 150 & 148 & 1 & 1 & \multirow[b]{2}{*}{0.00} \\
\hline & Poor & 253 & 105 & $2.38(1.72,3.28)$ & $2.00(1.40,2.85)$ & \\
\hline \multirow[t]{2}{*}{ Patient to nurse ratio } & $\leq 6$ & 165 & 121 & 1 & 1 & \multirow[t]{2}{*}{0.13} \\
\hline & $\geq 7$ & 238 & 132 & $1.32(0.96,1.81)$ & $0.77(0.55,1.08)$ & \\
\hline
\end{tabular}


Note: - AOR: adjusted odds ratio, COR: crude odds ratio, CI: confidence interval, EBP: Evidence-based practice 